\title{
DE DUNS ESCOTO A MARTIN HEIDEGGER
}

Antonio Pérez-Estévez*

RESUMEN - El objetivo de este ensayo es destacar el interés intelectual y la profunda relación de Heidegger con el pensamiento moderno y cercano a la vida de Duns Escoto. Asimismo señalar que ideas centrales del escotismo - heceidad, cognoscibilidad del individuo, posibilidad y contingencia, imposibilidad de pensar sin nombrar - aparecerán, reelaboradas y transformadas, en las ideas matrices heideggerianas: en el Dasein, en el Dasein como posibilidad y proyecto, en el ente como descubierto, en la identidad del conocimiento y el lenguaje.

PALABRAS-CLAVE - Historia de la Filosofía. Duns Escoto. Heidegger. Reelaboración de Conceptos.
ABSTRACT - The purpose of this essay is to underline Heidegger's intellectual interest and deep relation to Duns Scotus' modern and close to life thought. At the same time, it is pointed out that Scotus' fundamental ideas such as haecceity, the cognoscibility of the individual, possibility and contingency, impossibility of thinking without naming, will be retaken and transformed into Heidegger's parental ideas such as Dasein, Dasein as possibility and project, being as something unveiled, identity of knowledge and language.

KEY WORDS - History of Philosophy. Duns Scotus. Heidegger. Transformation of Concepts.

Los filósofos, como seres humanos, son espíritus incorporados, es decir, son seres humanos que viven en un tiempo y en un espacio, hablan y escriben en un idioma concreto, han recibido una educación determinada y pertenecen a una tradición. Heidegger nace en Baviera en 1889 y vive en el sur de Alemania hasta su muerte en 1976. Estudia filosofía y teología en el Seminario católico y fue discípulo de Husserl en la universidad de Marburgo. Estos datos escuetos nos indican que su formación filosófica se hallaba fundada en dos grandes columnas: la tradición escolástica medieval, especialmente el tomismo, y la fenomenología de Husserl. La influencia de la Fenomenología husserliana y sus raíces en Franz Brentano, ha sido siempre destacada como la fuente en la que se nutre el pensamiento de Heidegger ${ }^{1}$. De la influencia escolástica se ha hablado menos y casi siempre para señalar la importancia del problema del ser tanto en Tomás de Aquino como en Heidegger y la posible

* Universidad del Zulia, Venezuela.

1 La influencia de Franz Brentano fue muy marcada en sus años de juventud. De hecho, diserta y escribe ya en 1911: Besprechung: Franz Brentano, von der Klassifikation der psychischen Phänomene. En su tesis de doctorado (1913), Die Lehre vom Urteil im Psychologismus. Ein kritisch-positiver Beitrag zur Logik, la influencia de Brentano y Husserl es fundamental. 
influencia del primero sobre el segundo. Pero Heidegger sintió en su juventud un marcado interés no precisamente por Tomás de Aquino sino por Juan Duns Escoto, a quien apenas se estudiaba en los Seminarios católicos. La razón de ese interés por el Doctor Sutil, aparte de la posible influencia del Prof. Carl Braig, quien, en su curso de Metafísica, destacaba la importancia del Franciscano, fue su extraordinariamente crítica mentalidad en los problemas lógicos, su personalísima manera de pensar con aires de modernidad y su cercanía a la vida real, mayor y más sutil que la de los escolásticos anteriores a él ${ }^{2}$. La valoración positiva del individuo que se produce al atribuir la causa de la individuación a la formalidad de la heceidad, es una prueba, para Heidegger, de que el pensamiento de Escoto se aproxima a la vida real más que ninguno de los escolásticos anteriores. Y consecuencia de la plenitud de la vida es también la sutileza con la que retorna al mundo abstracto de la matemáticas. Debido a este interés, se decide a escribir su Tesis de Habilitación (1915) sobre Las categorías y la doctrina de la significación en Juan Duns Escoto. Hoy sabemos que la Gramática speculativa en la que basa una parte de su estudio, no pertenece a los escritos auténticos del Doctor Sutil ${ }^{3}$. Pero Heidegger realiza su lectura dentro del contexto total del pensamiento escotista, tal como se conocía en ese momento ${ }^{4}$, y cita continuamente obras que continúan siendo el núcleo mismo de ese pensamiento como son las Quaestiones super Libros Metaphysicorum, Opus Oxoniense (Ordinatio), Quodlibeta, Quaestiones in Libros Praedicamentorum, Reportata Parisiensia, Quaestiones in Libros Elenchorum ${ }^{5}$. Aparece sin duda como un profundo conocedor del pensamiento escotista especialmente en lo que concierne a los problemas que aborda, a saber, el problema - lógico-ontológico - de las categorías y el problema de la significación.

El estudio y atención (Aufmerksamkeit) que Heidegger prestó a Duns Escoto en sus años de juventud - tenía 26 cuando presentó su habilitación - ¿tuvo influencia en su pensamiento posterior? La respuesta no puede ser sino positiva. Nadie puede prescindir de sus años de formación y éstos marcan siempre el camino del pensar que uno va trazando en los largos años de vida.

Heidegger no cita ni una sola vez a Duns Escoto en sus textos, a partir de Sein und Zeit (1927). No necesitaba hacerlo. Duns Escoto, igual que Brentano, Dilthey o Husserl, forman parte esencial de ese fundamento filosófico, posiblemente

2 Gesamtausgabe. Band I. Die Kategorien und Bedeutungslehre des Duns Scotus, Vittorio Klostermann, Frankfurt am Main, 1978, p. 203: "Nicht allein die dem Duns Scotus mit Recht nachgerühmte und für logische Probleme so ausserordentlich notwendige kritische Denkart lenkte unsere Aufmerksamkeit gerade auf ihn. Bestimment ist seine ganze Denkerindividualität überhaupt mit ihren unverkennbar modernen Zügen. Er hat eine grössere und feinere Nähe (haecceitas) zum realem Leben, seiner Mannigfaltigkeit und Spannungsmöglichkeit gefunden als die Scholastiker vor ihm. Zugleich weiss er sich aber auch mit derselben Leichtigkeit aus der Fülle des Lebens weg in die abstrakte Welt der Mathematik zu wenden".

3 Ioannis Duns Scoti Doctoris Subtilis OFM Grammaticae speculativae nova Editio, cura et studio P. Mariani Fernández García, Quarachi, 1902.

4 Utiliza la edición Wadding-Vivès de Opera Omnia, París, 1891-1895.

5 Cita, como era inevitable en ese momento, también obras consideradas hoy de dudosa autoría como De Rerum Principio. 
inconsciente, que será la base de todo su pensamiento. Nosotros comenzaremos por resumir la Tesis de Habilitación o estudio sobre Las Categorías y la Teoría de la Significación en Juan Duns Escoto. Pasaremos, luego, a señalar las analogías existentes entre elementos fundamentales del pensamiento escotista y del pensamiento heideggeriano: el ente singular y la afinidad, incluso nominal, entre la haecceitas y el Dasein, la cognoscibilidad inteligible del ente singular y su carácter de descubierto, el ser creado como posible y el Dasein como proyecto y posibilidad, la relación palabra-pensamiento serán los cuatro puntos en los que nos detendremos. Estas analogías no nos deben conducir a la conclusión de que los sistemas filosóficos de Escoto y Heidegger son semejantes. Poco tiene que ver el sistema filosóficoteológico del Franciscano, enmarcado en el último cuarto del siglo XIII con el sistema filosófico de Heidegger producido en el medio historicista, vitalista y fenomenológico de la primera mitad del siglo XX. Pero, aún en modos y sistemas de pensamiento diferentes, existen ideas madres de Escoto que, digeridas y recreadas en una época y en un contexto cultural distintos, reaparecen como las columnas centrales del nuevo pensamiento.

Seguro que otros lectores han podido y podrán encontrar otros aspectos del pensamiento de Heidegger, en los que pueda advertirse la influencia de Duns Escoto ${ }^{6}$.

\section{Doctrina de las categorías y de la significación en Duns Escoto}

No es casual el interés de Heidegger por el más agudo y sutil de los escolásticos. Ni es tampoco casual su interés por el doble tema de las categorías y de la significación. Años más tarde, en el año 1954, en una visión retrospectiva, dirá que en su Tesis de Habilitación de 1915 se encontraban ya los dos grandes temas que serán el objeto principal de todos sus escritos: el problema del ser y el de la palabra. Afirmaba textualmente que

ya en el título de mi Habilitación en 1915, Las categorías y la doctrina de la significación en Duns Escoto, se ponían en evidencia estas dos perspectivas: 'Doctrina de las categorías' es, en efecto, el nombre tradicional dado al examen del ser de los entes; 'Doctrina de la significación' quiere decir gramática especulativa, es decir, la reflexión metafísica sobre la palabra en su relación con el ser?

El ser de las categorías y de la significación es entendido por Heidegger, a partir de una lectura husserliana, como objeto, es decir, en su relación a un entendimiento

6 Estudios sobre Heidegger y Duns Escoto, quiero citar solo dos publicados en los últimos años: MCGRATH, Sean J., "Heidegger and Duns Scotus on Truth and Language", The Review of Metaphysics, December 2003, n. 226, pp. 339-358. VETTER, Helmuth(Editor), Heidegger und das Mittelalter, Frankfurt am Main: Peter Lang, 1999.

7 HEIDEGGER, M., Unterwegs zur Sprache, Neske, 1986, pp. 91-92: "denn schon im Titel meiner Habilitationschrift aus dem Jahre 1915 Die Kategorien und Bedeutungslehre des Duns Scotus kamen die beiden Ausblicke zum Vorschein: Kategorienlehre ist der übliche Name für die Erörterung des Seins des Seienden; Bedeutungslehre meint die grammatica speculativa, die metaphysische Besinnung auf die Sprache in ihrem Bezug zum Sein". 
que lo conoce. No tiene sentido hablar de objeto sin sujeto, ni viceversa. El ser es máximamente cognoscible, máxime scibilis, debido a que es el objeto propio y adecuado del entendimiento. $Y$ es cognoscible en sumo grado debido que, como prioridad lógica, es el elemento primigenio, das Urelement, en virtud del cuál el objeto es objeto 0 , dicho de otra manera, es la condición de posibilidad de que haya objetos para el entendimiento. Es el fundamento del objeto como objeto. El ser, como fundamento del objeto, es también el trascendental absoluto o, como expresa en alemán, el último de los transcendentales, das Letzte. Los otros transcendentales, estudiados por Duns Escoto, lo uno y lo verdadero, son trascendentales derivados o secundarios. Son como elementos constitutivos del último y primigenio que es el ser.

Lo Uno como trascendental con el ser, viene a expresar la identidad de cada objeto. Heidegger lo expresa con la proposición "Lo algo es un algo, Etwas ist ein Etwas", que a simple vista parece una tautología pero que pone de manifiesto la relación que todo objeto encierra en sí mismo. Todo objeto encierra en sí mismo la doble relación de la identidad y la diferencia o heterótesis. El ser, en cuanto uno, es él mismo y, a la vez, distinto de los demás objetos. Es decir, la identidad y la alteridad o diferencia, lo uno y lo otro, están contenidos simultáneamente en el objeto en cuanto uno. Diferencia que, en términos lógicos, se expresa como contrariedad y no como contradicción. Lo otro es lo contrario de lo uno, debido a que, a pesar de la diferencia y la alteridad, mantiene, con el uno, algo de semejanza y de unión. La contradicción de lo uno sería la nada. La nada es, con respecto al ser o al uno, la alteridad absoluta, sin vínculo alguno real. Ahora bien, lo otro o la diferencia puede ser y es múltiple. Lo otro de lo uno es una multitud de entes. Por eso, el uno como determinación primera (Urbestimmung) del ser exige la multiplicidad, das Multum, de lo otro.

$\mathrm{Si}$ el ser es, antes que nada, objeto para un entendimiento, lo verdadero (o lo falso) es la característica de las actividades del entendimiento, a saber, de la simple aprehensión y del juicio. En la simple aprehensión no puede darse falsedad. Lo contrario de la simple aprehensión es la ignorancia. La simple aprehensión de un objeto por el entendimiento es siempre verdadera. El juicio es verdadero cuando la unión del predicado con el sujeto es válida. Lo verdadero no dice directamente nada del objeto sino que expresa la validez (o invalidez) lógica de un atributo predicado de un sujeto. El juicio es el auténtico y más original lugar de la verdad (o falsedad). El atributo predicado está válidamente unido al sujeto de la proposición y, a través de éste, al objeto. Heidegger, leyendo a Duns Escoto, va a trazar la línea divisoria que separa lo lógico de lo ontológico. El ente lógico no pertenece ni a la esfera del ente ontológico u objetivo ni a la esfera del ente psicológico o subjetivo. Es un ente de razón, ens rationis, que está en el alma pero que no pertenece al alma. El juicio, por ejemplo, es un acto del alma y, bajo ese aspecto, es una realidad psíquica. Pero la verdad (o falsedad) lógica de ese juicio expresa la validez o invalidez de la unión de los términos, es decir, la intencionalidad significativa de los mismos. Lo lógico manifiesta el orden y la relación que el entendimiento da a sus conceptos. El ámbito lógico posee, en consecuencia, categorías distintas del ámbito ontológico y del ámbito psicológico.

Lo lógico se objetiva en la palabra y en la proposición, hablada o escrita. El lenguaje y la gramática es la expresión fonética o escrita de lo lógico. Pero se 
distinguen. El orden inteligible de lo lógico no necesariamente se expresa en palabras. La palabra y el lenguaje, en sí mismo, ni posee intencionalidad ni significación. Para el que no conoce un idioma, al escucharlo, no se le muestra más que como ruido sin sentido. Sólo como expresión de conceptos y de juicios se abre el lenguaje a la posibilidad de significación y de comprensión. Las palabras y el lenguaje pertenecen a un mundo distinto del lógico. El lenguaje pertenece al mundo sensible, nace, cambia y desaparece. Lo lógico, por el contrario, pertenece a la esfera de las realidades que están fuera del tiempo y del espacio. Lo lógico se puede expresar de distintas maneras y en distintos idiomas y en él se encuentra la verdad y la falsedad. En el lenguaje y su gramática, en cambio, no se da verdad ni falsedad sino lo correcto o lo incorrectamente dicho. Lo lógico tiene prioridad sobre la palabra, el lenguaje y su gramática. La palabra significa sólo a través del concepto.

La palabra, el lenguaje es signo, indica, señala, da a entender. El signo nos remite a algo distinto a él mismo. El lenguaje, la palabra, como signo, indica y nos remite a otros signos, los conceptos y, a través de ellos, a los objetos en cuanto conocidos. El significado de la palabra es, por tanto, doble: significa en primer lugar un concepto del mundo lógico y, en segundo lugar, un objeto de la realidad exterior.

Heidegger descubre en Duns Escoto tres modos de ser objeto: el modus essendi, el modus intelligendi y el modus significandi. La característica del modus essendi es la existencia. La característica del modus intelligendi es lo pensado en cuanto pensado con su intencionalidad. La característica del modus significandi es la expresión y lo expresado en cuanto tal, en la medida que nos remiten a los conceptos y a los objetos. En resumen, el ser del objeto se muestra en y por la palabra y el lenguaje a través de los conceptos del entendimiento.

\section{De la haecceitas ${ }^{8}$ al Dasein}

Me llamó la atención desde el primer momento la semejanza entre las palabras, fundamentales para ambos autores, haecceitas y Dasein. Cada vez que me encuentro con Dasein, me viene a la mente la palabra haecceitas, tan característica del pensamiento escotista. Ambas son palabras, una latina y otra alemana, que indican y señalan algo concreto, singular, aunque dentro de sistemas de pensamiento muy distintos. Todo nombre es una llamada que trae a nuestra presencia lo ausente y también un signo o una señal que dice referencia a algo real y supone, es decir, está en su lugar. Estos nombres - haecceitas y Dasein- son llamadas que traen a nuestra presencia y a nuestra memoria presente o bien 'este ente' en el caso de haecceitas 0 bien 'este ser aquí' en caso de Dasein. No podemos asegurar que Heidegger, conscientemente, haya construido Dasein como una derivación de haecceitas. Pero no es aventurado afirmar que de su trato cotidiano con el pensamiento escotista y, en concreto, de la haecceitas medieval, nació el Dasein, el ser-ahí, de Heidegger. No me cabe duda de que el precedente de Dasein es la haecceitas.

8 El término haecceitas era relativamente común entre los pensadores de la segunda mitad del siglo XIII. Fue usado por Duns Escoto dos veces en Quaestiones subtilissimae super libros Metaphysicae y seis veces en Reportata Parisiensia. También lo usó, en esa misma época, Juan Quidort de París en su Determinatio. 
La palabra latina haecceitas, usada ya algunas veces por Duns Escoto y popularizada por su discípulo Antonio Andreas, es un sustantivo abstracto cuya raíz, haec, es la forma femenina del nominativo perteneciente al demostrativo hic, haec, hoc. Significa literalmente esteidad y se refiere al elemento positivo y formal que Duns Escoto elaboró como principio de individuación de toda sustancia creada. Es decir, significa el elemento formal y positivo por el que una sustancia se convierte en ésta sustancia concreta y determinada. La heceidad es, para Duns Escoto, la cuasi forma que determina y perfecciona a la naturaleza común (quididad o esencia específica) para constituir una sustancia concreta y determinada, un esto. Supuso una concepción nueva, dentro de la tradición del pensamiento occidental, al considerar al individuo como una realidad más completa y perfecta que la realidad universal de la esencia específica o quididad. La heceidad o principio de individuación añadía perfección y ser a la escuálida realidad de la naturaleza común, para, juntas, constituir la sustancia individual. El individuo o sustancia individual, en razón del elemento individuante, tenía, por tanto, más ser y era más cognoscible que la naturaleza común o esencia universal correspondiente ${ }^{9}$. El universal, por primera vez, poseía una consistencia óntica menor que la del individuo. Hasta ese momento, desde los viejos tiempos platónicos, el ser estaba vinculado sólo a la forma o idea y ésta era solo y necesariamente universal ${ }^{10}$. El individuo, en cuanto tal, se perdía, para Platón, entre las sombras del mundo que se engendraba y perecía, y formaba parte de la pseudo-realidad sensible. Para Aristóteles, el individuo, en cuanto tal, estaba vinculado a la obscura realidad de la materia y, por tanto, no poseía un auténtico ser ni era cognoscible. El ser, en la sustancia compuesta o ovvohov, provenía de la forma que, a su vez, era en sí misma universal.

Dasein es una palabra alemana, compuesta del adverbio espacio-temporal da y del verbo sustantivado Sein, ser, que literalmente significa el ser (que está) aquí. El ser señalizado aquí por el adverbio da, es este ser humano concreto, único ser finito capaz de tener una especial apertura al ser y de preguntarse por él. Dasein no es un sustantivo que pueda significar el ser humano o cualquier ser humano. Fijémonos cómo describe Heidegger el Dasein:

El ser ahí es, en cuanto tal, en cada caso 'este'; con su ser es descubierto esencialmente ya una ilación de entes 'a la mano' - el ser ahí en cuanto es, 'se ha referido' en cada caso ya a un mundo que hace frente; a su ser es esencialmente inherente este 'estado de referido $\mathrm{a}^{\prime 11}$.

9 Es de advertir que la naturaleza común o quididad de una sustancia individual es considerada por Escoto como universal material o universal in re. De hecho, no es un verdadero universal, debido a que, en sí misma, es sólo indiferente y no le repugna ser ya sea individual, unida a la heceidad, ya sea universal por obra del entendimiento. Los universales propiamente dichos desaparecen de la realidad extra-mental en el pensamiento escotista. Quedan reducidos a conceptos con sus nombres respectivos.

10 Ver sobre la heceidad y su realidad ontológica: PÉREZ-ESTÉVEZ, A. "El individuo en Duns Escoto", Cuadernos Salmantinos de Filosofía, 1996 (XXIII), pp. 86-146.

11 HEIDEGGER, M., Sein und Zeit, Max Niemeyer, Tübingen, 1972, n. 18, p. 87: "Dasein ist als solches je dieses, mit seinem Sein ist wesenhaft schon ein Zusammenhang von Zuhandenem entdeckt.- Dasein hat sich, sofern es ist, je schon auf eine begegnende 'Welt' angewiesen, zu seinem Sein gehört wesenhaft diese Angewiesenheit" (Sigo, en general, en Ser y Tiempo, la traducción de José Gaos, aunque frecuentemente con modificaciones mías). 
Dasein es siempre un ser humano concreto, un éste, que se abre a un conjunto concreto de entes que le son útiles y que se refiere ya a un mundo que se le enfrenta. El Dasein encierra en su ser una referencia a un singular y concreto mundo circundante.

Dasein es este ser abierto a un mundo determinado y con una exsistencia concreta, es decir, con unas posibilidades concretas para realizarse. El ser del Dasein no es un ser hecho con una esencia fija y determinada, como quería la Metafísica tradicional, sino que es un ser que exsiste, es decir, que se despliega en un proyecto. Más que realidad, el Dasein es pura posibilidad, es un hacerse.

\section{Del ser posible en Duns Escoto al Dasein como posibilidad de ser en Heidegger}

Al poder ser, en cuanto poder ser otro, al cambiar o devenir, lo explica racionalmente Aristóteles por primera vez en el pensamiento occidental. Cuando echa mano de las nociones de potencia y acto, de materia y forma, ofrece la primera teoría racional consistente del cambio y del continuo devenir en la naturaleza. La materia prima, como pura potencia de ser, es el sustrato o sujeto último en el que se esconde, en toda sustancia primera o natural, la infinita posibilidad de ser algo distinto o de recibir nuevas formas ya sean éstas accidentales ya sean éstas sustanciales. Pero el cambio natural, explicado por Aristóteles, es un cambio que está desde siempre prefijado y predeterminado, lo que significa que tal sustancia puede cambiar, recibir nuevas formas para convertirse en algo distinto de muchas maneras pero siempre de acuerdo a la normativa universal de la causalidad eficiente y de sus efectos necesarios. La materia o sujeto de cambio no tiene la capacidad de actuar y elegir, entre dos o más, la nueva forma que va a recibir, debido a que es sólo posibilidad o potencia pasiva para recibir una forma. El cambio está predeterminado por la causa eficiente y la forma que la materia está dispuesta a recibir. La semilla del peral no tiene otra opción sino la de convertirse en peral. La madera está sólo en potencia pasiva para recibir la forma que la causa eficiente (el carpintero) quiera darle, ya sea la forma de puerta o de cama. La posibilidad para una sustancia compuesta o natural de auto-determinarse, no es posible en la doctrina del acto y de la potencia aristotélica. Lo que pasa en el universo aristotélico está siempre teñido de verdad y de necesidad. De ahí que la explicación de acciones contingentes futuras - acciones humanas futuras que no son ni verdaderas ni falsas debido a que no son predecibles - queda en la penumbra del concepto de libertad apenas desarrollado.

Serán los pensadores medievales quienes intentarán conjugar la libertad humana con la providencia y la predestinación, actividades, a su vez, producto de la libertad y omnipotencia divinas. Será Duns Escoto quien introduce, en el pensamiento medieval, la radical contingencia como la característica fundamental de todo lo creado $\mathrm{y}$, de esa manera, da un mayor peso a la libertad tanto divina como humana. Contingencia que significa que todo el universo creado pudo, puede y podrá ser de otra manera y/o dejar de ser. El poder-ser de otra manera o el poder-no-ser está en la raíz ontológica de todo ser creado. Este poder-ser distinto o poder-no-ser de toda 
criatura deriva de la voluntad infinitamente libre con la que Dios creó este universo ${ }^{12}$. La infinita libertad de Dios implica, en efecto, la absoluta indeterminación de $\mathrm{Su}$ voluntad y $\mathrm{Su}$ omnipotencia para querer y producir todo lo posible, es decir, todo lo que no encierre contradicción. La libertad y la omnipotencia absoluta de Dios tienen como único límite el principio de contradicción o lo imposible a lo que le repugna existir ${ }^{13}$. Todo lo que no sea contradictorio o imposible es lógicamente posible y puede ser producido por la potencia absoluta y libre de Dios. Lo posible es aquello que incluye formalidades a las que no le repugna unirse y, en consecuencia, está dentro de la esfera de lo producible por la omnipotencia libre de Dios ${ }^{14}$. La infinita libertad de la voluntad divina ha de entenderse de la siguiente manera: con un mismo y único acto volitivo, pudo y puede querer y producir objetos distintos y opuestos. Es decir, Dios en Su omnipotencia y en Su infinita libertad, con el mismo acto volitivo con el que quiso y creó este universo, pudo haber querido y creado otro u otros universos distintos, simultáneos o sucesivos a éste. En consecuencia, este universo pudo (y puede) ser de otra manera o puede no-ser. Y entendemos por universo todo lo creado conocido con su correspondiente orden físico y moral. En consecuencia, para Duns Escoto, es perfectamente posible la existencia, simultánea o sucesiva, de otro u otros mundos, todavía desconocidos para nosotros, con otro orden físico y con otro orden moral. Todo lo creado puede ser de otra manera o puede dejar de ser.

Lo necesario, lo estrictamente necesario, desaparece en Duns Escoto del universo creado. Lo necesario quedará como característica reservada a la Divinidad y al mundo lógico de los seres posibles. No se insiste con frecuencia lo suficiente en la importancia que tiene la noción de ser posible dentro del pensamiento de Duns Escoto. El pensamiento de Duns Escoto contiene un mundo, distinto y anterior a éste, de seres posibles, de seres que pueden llegar a existir. Es el mundo lógico, increado y paralelo a Dios, en el que rige la necesidad absoluta del principio de no contradicción, que se expresa por medio de la no repugnancia en la unión de dos 0 más formalidades. A la necesidad de este mundo lógico está subordinado incluso el mismo Dios ${ }^{15}$.

El ser humano, para Duns Escoto, se distingue de la naturaleza y se asemeja a Dios no en razón de su entendimiento sino en razón de la libertad de su voluntad. Libertad que consiste en que la voluntad, esencialmente indeterminada para actuar, ella misma es la causa suficiente y eficiente de su auto-determinación. La voluntad

12 Lectura I, dist. 39, q. 1-5, n. 41 (Opera Omnia, edición Vaticana, t. XVII, p. 492): "dico quod oportet causam istius contingentiae assignare a parte causalitatis Dei, quia non potest effectus aliquis contingenter provenire a causa secunda nisi prima causa in illo ordine contingenter moveat [...] et ideo causa contingentiae in entibus est ex hoc quod prima causa contingenter, et non necesario, movet".

13 Ordinatio I, dist. 43, q. unica, n. 5 (Opera Omnia, Edición Vaticana, t. VI, p. 353-4): "illud ergo est simpliciter impossibile cui per se repugnat esse, et quod ex se primo est tale quod sibi repugnat esse, - et non propter aliquem respectum ad Deum, affirmativum vel negativum, immo repugnaret sibi esse, si per impossibile Deus non esset".

14 Lectura I, dist. 39, q. 5, n. 49 (Opera Omnia, edición Vaticana, t. XVII, p. 494): "potentia logica non est aliqua nisi quando extrema sic sunt possibilia quod non sibi invicem repugnant sed uniri possunt, licet non sit possibilitas aliqua in re".

15 Ver el texto de la nota anterior. 
humana no se encuentra jamás determinada a una sola acción volitiva y a un solo objeto. Puede siempre elegir, entre al menos dos actos volitivos opuestos (a y -a), uno de los dos y, entre dos objetos distintos $(\mathrm{A}$ y $-\mathrm{A})$, querer y realizar uno de ellos. Una vez elegido un acto volitivo y un objeto, en ese mismo instante, no puede a la vez querer otro objeto distinto; pero, tiene siempre la posibilidad de cambiar y de producir, en momentos distintos, actos volitivos distintos y tender y producir objetos distintos ${ }^{16}$. De aquí que el ser humano tiene la posibilidad de llenar su vida con actos elegidos entre, al menos, dos distintas posibilidades y tender a objetos elegidos entre, al menos, dos distintos. Si todo ser creado es radicalmente contingente, los actos libres de la voluntad humana son doblemente contingentes. Es, en consecuencia, imposible saber de antemano de manera necesaria lo que un ser humano va a querer y a realizar mañana. Ni Dios mismo, afirma Duns Escoto, puede saber de manera necesaria lo que un ser humano querrá y hará mañana ${ }^{17}$. Dios mismo no puede saber necesariamente si un ser humano se salvará o se condenará. El Doctor sutil defiende que incluso un ser humano predestinado puede condenarse, debido a que su libre voluntad puede tomar la decisión de pecar, de no arrepentirse y, por tanto, condenarse. Por primera vez, en la tradición cristiana, el ser humano puede decir no a la decisión divina de predestinarlo. La radical libertad, es decir, la permanente posibilidad que el ser humano tiene para elegir entre distintas posibilidades y la imposibilidad absoluta de predecir lo que hará en el futuro, serán características fundamentales del pensamiento escotista. El ser humano escotista es siempre posibilidad de ser otro y de no-ser.

Todo Ser y Tiempo es un esfuerzo por explicar el ser del Dasein como posibilidad. El ser ahí es exsistencia, posibilidad de ser o, en palabras de Heidegger, la 'sustancia' del hombre no es el espíritu, como síntesis de alma y cuerpo, sino su exsistencia. Y existencia equivale a posibilidad de ser y de hacerse. La posibilidad en cuanto existenciario, afirma en un texto, es la más original y última determinación ontológica positiva del ser ahí. Por eso expresa: "más alta que la realidad es la posibilidad, höher als die Wirklichkeit steht die Möglichkeit"18. O en otro texto:

el ser ahí se comprende siempre a sí mismo partiendo de su existencia, de una posibilidad de ser él mismo o no él mismo ${ }^{19}$.

Va a ser la gran diferencia entre el Dasein y los entes. Los entes útiles o que están a la mano y los entes ante los ojos, son cosas que utilizamos o que nos enfrentan, y que las comprendemos como relativas a nosotros y teniendo posibilidades. Pero al Dasein, nuestra particular manera humana de ser, la debemos comprender como

16 Lectura I, dist. 39, q. 1-5, n. 45 (Opera Omnia, t. XVII, p. 493): "voluntas enim nostra libera est ad actus oppositos (ut ad volendum et nolendum, et amandum et odiendum), et secundo mediantibus actibus oppositis est libera ad obiecta opposita ut libere tendat in ea, et tertio est libera ad effectus quos producit sive immediate sive movendo alias potentias exsecutivas".

17 Ver sobre el problema de la libertad en Duns Escoto: PÉREZ-ESTÉVEZ, A. "Libertad en Duns Escoto", Revista Española de Filosofía Medieval, 11 (2004), p. 97-117.

18 HEIDEGGER, M., Sein und Zeit, Tübingen: Max Niemeyer Verlag, 1972, p. 38.

19 Ver nota n. 20. 
esencial posibilidad, como proyecto, como apertura a su poder ser. Detengámonos a analizar algunos textos que nos ayuden a una mejor comprensión del Dasein como posibilidad.

El ser ahí se comprende siempre a sí mismo partiendo de su existencia, de una posibilidad de ser él mismo o no él mismo. Estas posibilidades o las ha elegido el ser ahí mismo, o éste ha caído en ellas o crecido en cada caso ya en ellas ${ }^{20}$.

Pero la posibilidad de ser se divide o bien en posibilidad de ser él mismo o bien en posibilidad de no ser él mismo. Si la posibilidad de ser la ha elegido el Dasein mismo, es una posibilidad auténtica de ser: es él mismo. Pero si la posibilidad no la ha elegido el Dasein, en ese caso no es una posibilidad auténtica de ser, sino que más bien ha caído en ella o ha crecido inconscientemente en ella: no es él mismo.

$\mathrm{El}$ que la posibilidad de ser del ser ahí sea auténtica y propia o inauténtica e impropia, es un tema reiterativo a lo largo de Ser y Tiempo. Veamos un texto en el que insiste en esta doble posibilidad de ser:

Por ser en cada caso el ser ahí esencialmente su posibilidad, puede este ente, en su ser, elegirse a sí mismo, ganarse y también perderse, o no ganarse nunca o solo parece ser que se gana. Haberse perdido y no haberse ganado sólo lo puede en tanto es, por su esencia misma, posible ser ahí propio, es decir, apropiado por sí mismo y para sí mismo. Los dos modos de ser de la propiedad y la impropiedad[...] tienen su fundamento en que todo ser ahí se caracteriza por 'ser, en cada caso, mío' ${ }^{21}$.

El ser ahí es su posibilidad. En eso se distingue de algo a la mano o útil, como los instrumentos que nos rodean, que se limitan a tener posibilidad o posibilidades, o a que la posibilidad les sea sólo una peculiaridad o característica. La posibilidad propia o impropia de ser se deriva de la radical libertad del ser ahí. Libertad que consiste en la posibilidad de elegir ganarse o perderse, o no ganarse nunca o solo parece ser que se gana. Ganarse o perderse del ser ahí, solo son posibles en tanto que, por su esencia, al ser ahí le es posible un ser propio o apropiado por sí mismo y para sí mismo o un ser impropio por sí mismo y para sí mismo. Es decir, el poder ser propio o impropio del ser ahí, se fundamentan en el hecho de que cada ser ahí es su propio y particular poder ser. De ahí que el poder ser del ser ahí no es un poder ser abstracto análogo a la libertas indifferentiae. El ser ahí, en cada caso, por encontrarse en un mundo determinado, está abierto a determinadas posibilidades. Y entre esas posibilidades determinadas, elige una, la sigue y la amarra, y abandona y deja pasar otras. Cada ser-ahí es lo que él puede ser, su determinada posibilidad. Heidegger resume su idea fundamental, expresando que

20 Heidegger, M., Sein und Zeit, p. 12: "Das Dasein versteht sich selbst immer aus seiner Exsistenz, einer Möglichkeit seiner selbst, es selbst oder nicht es selbst zu sein. Diese Möglichkeiten hat das Dasein entweder selbst gewählt, oder es ist in sie hineingeraten oder je schon darin aufgewachsen".

21 Op. cit., p. 42-43: "Und weil Dasein wesenhaft je seine Möglichkeit ist, kann dieses Seiende in seinem Sein sich selbst 'wählen', gewinnen, es kann sich verlieren, bzw. Nie und nur 'scheinbar'gewinnen. Verloren haben kann es sich nur und noch nicht sich gewonnen haben kann es nur, sofern es seinem Wesen nach mögliches eigentliches, dass heisst sich zueigen ist. Die beiden Seinsmodi der Eigentlichkeit und Uneigentlichkeit [...] gründen darin, dass Dasein überhaupt durch Jemeinigkeit bestimmt ist". 
el ser-ahí es ser posible entregado a la responsabilidad de sí mismo, es plena y total posibilidad arrojada ${ }^{22}$.

Como poder ser, al ser-ahí le es inherente la proyección, el ser abriéndose a su poder ser. Y puede, el ser-ahí, comprenderse o bien por el mundo y por los otros 0 bien por su más propio poder ser. Comprenderse por el mundo y por los otros, quiere decir que el estado de abierto del ser-ahí es una apertura impropia en la que no se alcanza la plenitud ontológico-existenciaria. Por el contrario, comprenderse por el propio poder ser es abrirse de manera auténtica y alcanzar así la verdad de la existencia y la plenitud ontológica y existenciaria.

El ser-ahí puede comprenderse por el mundo. Es el estado en que el ser-ahí no está abierto al mundo sino que se encuentra caído y perdido en él. Estado que Heidegger califica de desfigurado y cerrado por obra de las habladurías, la avidez de las novedades y la ambigüedad. El ser-ahí, en este estado, se encuentra arrancado de sus raíces y es en la falsedad.

Relación con este estado de caído y perdido en el mundo, tiene también cuando el ser-ahí se comprende por los otros. Decimos que el ser-ahí es en su cotidianidad. Está bajo el dominio de los otros que le arrebatan el ser. El ser-ahí es uno con los otros y no se distingue de ellos. El ser-ahí quiere y elige lo que los otros quieren y eligen: lee, come, viste, se divierte como los otros leen, comen, visten y se divierten. Es el estado del ser, del uno, de elegir las posibilidades de los otros y dejarse hacer por lo que dicen los demás.

El poder ser del ser-ahí se expresa en un poder ser en el mundo, un poder ser con los otros y un poder ser relativamente a sí mismo. Poder ser que se comprende como curarse del mundo, curarse de los otros y en todo momento curarse de uno mismo. La relación del ser-ahí con el mundo - con lo a la mano y con lo ante los ojos - y con los otros determina sus posibilidades y le permite elegir en cada caso. El ser-ahí, por el hecho de ser esencialmente existencia o poder ser, no se comprende nunca como realizado o terminado. Es siempre más de lo que efectivamente es, pues, en razón de su poder-ser, lo que aún no es, lo es existenciariamente. La apertura del ser-ahí al poder-ser, no se cierra mientras sea ser-ahí. Por eso, aún cuando no alcance a ser alguna de sus posibilidades, estará siempre abierto a ella, lo que hace que tal posibilidad sea parte de su ser como abierto o como exsistencia. La muerte es, para el ser-ahí, la posibilidad que cierra toda otra posibilidad. O, como dice Heidegger, la muerte es la posibilidad de la total imposibilidad del ser-ahí23.

\section{De la cognoscibilidad del individuo escotista al mostrarse de los entes en Heidegger}

Al menos desde Platón y Aristóteles, los entes existentes en el tiempo estaban recubiertos de una opacidad que los hacía incognoscibles al entendimiento humano.

22 Op. cit., n. 31, p. 144: "das Dasein ist ihm selbst überantwortetes Möglichsein, durch und durch geworfene Möglichket".

23 Sein und Zeit, n. 50, p. 250: "Der Tod ist die Möglichkeit der schlechthinnigen Daseinsunmöglichkeit". 
El mundo natural que se engendra, se mueve y deja de ser, se ofrece sólo a los sentidos para producir un conocimiento sensible, doxa u opinión, lleno de imperfección y en el que no habita la verdad. Es preciso superar ese conocimiento sensible e individual y alcanzar, a través de un proceso dialéctico o intelectivo-abstractivo, el conocimiento universal de las formas o esencias para que podamos hablar de verdadero conocimiento, de episteme. El mundo de lo singular es, para Platón, un mundo de sombras o copias y, para Aristóteles, un mundo atrapado en la materia que es lo mismo que decir oscurecido por el misterio de un no-ente que no alcanza a ser la nada. Esta opacidad e incognoscibilidad de los entes naturales va a mantenerse, bajo la influencia de Platón y Aristóteles, a lo largo de toda la Edad Media hasta la segunda mitad del siglo XIII, Tomás de Aquino inclusive. La individualidad será, como la materia prima a la que está vinculada, una suerte de extraño no-ente o pura potencia de ser, imposible de ser aprehendido por el entendimiento humano.

Esta suerte de menosprecio ontológico y epistemológico por los individuos existentes va a ser superado en Duns Escoto. El individuo dejará de estar unido y causado por la materia para ser producido por una especie de forma o formalidad llamada heceidad. La singularidad deja de ser una suerte de no-ser y de imperfección, para convertirse en una perfección óntica añadida a la esencia o naturaleza común. Es una determinación formal o perfección ontológica por la que la especie se contrae, se individualiza y puede existir ${ }^{24}$. Así, para Duns Escoto, Juan o María poseen la perfección de la singularidad añadida a la perfección específica de la humanidad. Los entes naturales existentes pierden su opacidad tradicional para convertirse en abiertos al conocimiento no solo de los sentidos sino también del entendimiento. Dios y los ángeles, con su entendimiento perfecto, conocen al individuo en sí mismo y su conocimiento no se deriva del conocimiento de la especie ${ }^{25}$. El hecho de que al entendimiento humano le sea difícil conocer lo singular en sí mismo, depende de su imperfección. El individuo está abierto a la luz epistemológica de manera semejante a como el sol lo está a la visión de los humanos; pero no puede ser conocido por el entendimiento humano, acostumbrando, como la lechuza, a la imperfecta claridad de las tinieblas.

Los entes, también para Heidegger, se presentan y se muestran para que el Dasein por medio del entendimiento los descubra. Deteniéndose en el significado etimológico de la palabra griega $\alpha-\lambda \eta \theta \varepsilon 1 \alpha$ derivada de $\alpha-\lambda \eta \theta \varepsilon v \omega$ y éste, a su vez, derivado de $\alpha-\lambda \alpha v \theta \alpha v \omega$ - no ocultar -, va a describir la verdad de la proposición como el descubrimiento del ente en sí mismo. La palabra o el lenguaje permite al

24 Lectura II, 3, I, 6, n. 171: "Unde sicut in eadem re sunt diversae perfectiones formales sive entitates formales (ut in albedine), a quarum una accipitur intentio generis (ut intentio coloris), et alia entitas formalis a qua accipitur intentio differentiae (albedinis) [...] sic est entitas positiva in eadem re a qua accipitur natura specifica, et entitas formaliter alia a qua accipitur differentia ultima individualis, quae est omnino haec cui repugnat omnimoda divisio".

25 Lectura II, 3, 1, 5-6, n. 180: "dico quod singulare non intelligitur intellecta specie, et quod singulare intelligitur per se ab intellectu qui potest omnis intelligere intelligibilia (sicut Deus et similiter angelus). Unde quod non intelligatur per se ab intellectu nostro, hoc non est ex parte singularis, sed ex imperfectione intellectus nostri". 
ente en sí mismo mostrarse ( $\alpha \pi 0 \phi \alpha v \sigma \varsigma)$, y hacerlo como ente descubierto. El ente, en cuanto objeto, se muestra y se ofrece al entendimiento para que éste lo descubra y lo determine por medio del logos, de la palabra, de la proposición verdadera. Y este proceso de descubrir los entes que se muestran, sólo es posible para un Dasein abierto a un mundo que equivale a decir que es al lado de entes intra-mundanos. De un lado, el estado de abierto a un mundo, constitutivo del Dasein, es condición necesaria para descubrir los entes de ese mundo que se ofrecen y se muestran como fenómenos. De otro lado, los entes intra-mundanos que se muestran, no adquieren el estado de descubiertos hasta que el entendimiento del Dasein no los descubra y los haga manifiestos por medio del logos en una proposición verdadera. El Dasein, por obra de la palabra en una proposición verdadera, es el descubridor de los entes que se muestran y los entes se convierten, por esa misma acción del Dasein, en descubiertos.

En su lectura de Kant y el problema de la Metafísica, achaca a la finitud de nuestro ser y de nuestro conocimiento la capacidad de ser descubridores del ente. Si fuéramos seres infinitos, crearíamos los entes y, por eso mismo, los intuiríamos en un conocimiento perfecto. Pero somos seres finitos, con una existencia finita entregada al mundo de los entes, y estamos determinados para recibirlos, lo que significa que nuestra existencia debe dar al ente la posibilidad de presentarse ${ }^{26}$. Como nuestra intuición no es ni creadora ni activa sino una intuición receptiva, es preciso que el objeto óntico se nos ofrezca y se nos muestre él mismo como fenómeno, para que nosotros podamos recibirlo. Los objetos son fenómenos -y no hay algo más en el ente, distinto del fenómeno, que sea ente en sí - por el hecho de que son objetos para un entendimiento y un conocimiento finito ${ }^{27}$.

\section{Pensamiento y lenguaje}

Es sabido que Platón sostuvo, en su concepción dual del ser humano, que el diálogo escrito o hablado podía ser el peldaño para elevarse al pensamiento puro por el que descubriríamos la verdad oculta en el mundo de las ideas. En el Critón (46b), Sócrates propone investigar ambos - Critón y Sócrates - y aceptar sólo la mejor de las opiniones o la más racional en la que habita la verdad, con el objeto de llegar juntos a la conclusión verdadera que dé respuesta al deseo de Critón de que Sócrates debe escapar de la ciudad y huir de la muerte antes del alba. Pero no siempre Platón defendió la necesidad del diálogo o conversación entre varias personas como medio para alcanzar la Verdad. De hecho, defendió (Teeteto, 189e-190ª la posibilidad de "una conversación del alma consigo misma, preguntándose y respondiendo, afirmando y negando". Pareciera que el alma platónica es capaz de conversar consigo

26 HEIDEGGER, M., Kant und das Problem der Metaphysik, Frankfurt am Main: Klostermann, 1973, p. 25: "weil unser Dasein ein endliches ist - inmitten des schon Seienden existierend, an dieses ausgeliefert deshalb muss es notwendig das schon Seiende hinnehmen, d.h. dem Seienden die Möglichkeit bieten, sich zu melden".

27 Op. cit., p. 30: "Das Seiende 'in der Erscheinung' ist dasselbe Seiende wie das Seiende an sich, ja gerade nur dieses. Es allein kann ja als Seiendes, obzwar nur für eine endliche Erkenntnis, Gegenstand werden". 
misma sin necesidad de palabras, en una suerte de desdoblamiento puro por medio del cuál dialoga consigo misma. Al final de sus días, llegó a decir que el lenguaje exterior y fonético con otras personas, en concreto con Clinias, (Leyes X, 893ª) puede ser, incluso, un obstáculo a la preparación de nuestra mente para descubrir la verdad. La palabra, hablada o escrita, queda reducida en el pensamiento platónico a un recubrimiento sensible, corpóreo y accidental del pensamiento puro del alma. La Verdad es una realidad lumínica del mundo de las ideas a la que tienen acceso sólo algunas personas por medio de una intuición, sin palabra alguna, con dificultad y en contados momentos. De manera muy imperfecta, puede expresarse por medio de lenguaje sensible y corpóreo en proposiciones habladas o escritas. Esta duplicidad de lenguajes, el puro del alma sin palabras y el impuro y sensible del cuerpo, va a ser el pensamiento generalizado a lo largo de la Edad Media.

Duns Escoto distingue, en el ser humano, entre el conocimiento intelectivo y confuso de la singularidad (simplex aprehensio) y el conocimiento abstractivo de la esencia de una sustancia individual. Por el conocimiento confuso de la singularidad, el entendimiento humano conoce la existencia de la sustancia. Por el conocimiento abstractivo, el entendimiento conoce la quididad o esencia de la sustancia, expresada en su definición. El conocimiento de la singularidad es confuso, no por la singularidad en sí o heceidad, que, como hemos dicho, es en sí misma una formalidad luminosa, sino por la deficiencia del entendimiento humano en este estado de pecado en que nos encontramos. Dios y los ángeles, en razón de la perfección de su entendimiento, conocen por intuición perfectamente todos los seres, que son seres individuales. En el proceso abstractivo, en el que intervienen el fantasma y el entendimiento agente, se produce el conocimiento esencial por medio de la producción del universal propiamente dicho. Universal auténtico o lógico que será reducido a un nombre concreto con su concepto predicable de muchos sujetos ${ }^{28}$. No existe auténtico universal hasta que no se nombra. El universal indeterminado en acto que es la especie inteligible, no se convierte en verdadero y pleno universal determinado sino cuando se le da un nombre concreto que es, con el concepto correspondiente, predicable de muchos sujetos. Nombrar la especie inteligible o universal indeterminado en acto, significa transformarlo en un concepto determinado o auténtico universal, llamado por Duns Escoto universal lógico, cuya característica es el ser predicable de los individuos subsumidos bajo ese nombre y ese concepto ${ }^{29}$. Unidad e identidad de nombre y de concepto determinado, con la que Duns Escoto

28 Quaestiones subtilissimae in Metaphysicam Aristotelis, q. 18, n. 6 (Opera Omnia, edición Vivès, t. VII, p. 456): "[Universale] sumitur, vel sumi potest tripliciter: quoniam pro intentione secunda quae scilicet est quaedam relatio rationis praedicabili, et huc respectum significat hoc nomen universale in concreto, sicut et universalitas in abstracto".

29 Para Duns Escoto existen 3 tipos de universal: a) el universal in re o material - la naturaleza común - que no es propiamente universal sino que es indiferente a devenir singular unido a la heceidad o universal por acción del entendimiento; b) el universal metafísico o universal indeterminado en acto - especie inteligible - producto de la acción co-causada por el entendimiento agente y el fantasma; c) el universal determinado o lógico que consiste en el nombre y el concepto correspondiente. Sólo el último es el universal completo 0 auténtico. 
abre la senda de quienes defienden la imposibilidad de pensar y entender sin nombrar. Es decir, está abriendo el camino de quienes defenderán la identidad indisoluble de pensamiento y palabra. La verdad, que se encuentra en un juicio, se hace realidad siempre en el lenguaje, expresada en una proposición hablada o escrita. No existe, por tanto, para Duns Escoto -y desde luego menos para su discípulo Guillermo de Ockham - ni verdaderos conceptos sin palabras, ni pensamiento puro sin lenguaje.

Si para Duns Escoto, el proceso de conocer culmina con el nombre del concepto, para Heidegger ni siquiera puede iniciarse el conocimiento por la simple percepción sin palabras. Ya en 1925 escribió que

es un hecho que nuestras más simples percepciones y estados constitutivos están ya expresados, es más, están interpretados de alguna manera. No es tanto que veamos primero y originalmente los objetos y las cosas sino más bien que antes hablamos sobre ellas. Con más precisión, no decimos lo que vemos sino, más bien a la inversa, vemos lo que uno dice sobre el asunto ${ }^{30}$.

Las aparentemente más simples percepciones se producen ya en la palabra y, en consecuencia, están de alguna manera interpretadas. No percibimos nada aisladamente sino dentro de una totalidad o de un mundo en el que cobra sentido y significado. Pero esa totalidad y ese mundo ha sido construido y comprendido en la medida en que ha sido expresado en palabras. No es la percepción la que condiciona nuestro lenguaje sino, al revés, nuestro lenguaje y nuestro hablar condicionan nuestras percepciones.

También en Sein und Zeit se va a insistir en la identidad de conocer y decir. La antigua doctrina de que primero conocemos por medio de conceptos o pensamos y después expresamos esos conceptos en palabras, es desechada y sustituida por la identidad del conocer o pensar y el decir.

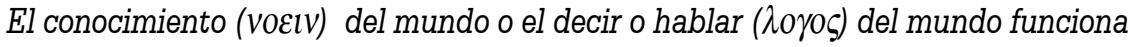
por tanto como el modo primario del ser en el mundo, afirma Heidegger ${ }^{31}$.

Conocer el mundo como acción teórica, equivale a decir algo del mundo. Y tal acción es el modo primario o la primera dimensión del ser en el mundo. El más primigenio conocimiento del mundo que se produce en la percepción, es ya sonora de palabras.

Percibir, insiste, tiene la plena realización en el decir y el hablar de algo que es algo $0^{32}$.

No se da percepción y conocimiento alguno sin rumor de lenguaje.

30 HEIDEGGER, M. Gesamtausgabe. Prolegomena zur Geschichte des Zeitbegriffs. Band 20., p. 75: "Faktisch ist es auch so, dass unsere schlichtesten Wahrnehmungen und Verfassungen schon ausgedrückte, mehr noch, in bestimmter Weise interpretierte sind. Wir sehen nicht so sehr primär und ursprünglich die Gegestände und Dinge, sondern zunächst sprechen wir darüber, genauer sprechen wir nicht das aus, was wir sehen, sondern umgekehrt, wir sehen, was man über die Sache spricht".

31 Sein und Zeit; n. 12, p. 59: "Erkennen von Welt (noein), bzw. Das Ansprechen und Besprechen von 'Welt'

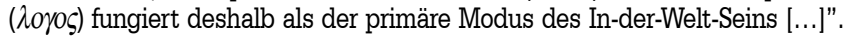

32 Op. cit., n. 13, p. 62: "Das Vernehmen hat die Vollzugart des Ansprechens und Besprechens von etwas als etwas". 
Pensar, dice el último Heidegger, es en el fondo preguntar, hacer y hacerse preguntas. Pero el comienzo de toda pregunta se produce primero en el corazón de una palabra en la que viene a decirse lo que está encerrado en la pregunta ${ }^{33}$. De ahí que lo propio del pensamiento no sea tanto el preguntar sino el escuchar, el prestar la oreja a la palabra en la que se promete lo que deberá venir en la pregunta. Pensar es dejar que la palabra nos hable y a la que nosotros debemos prestarle el oído y la atención. La palabra porta y trasporta el conjunto de las cosas y, sin ella, el mundo, incluido el yo, desaparece en la oscuridad de la ignorancia. Conocer, pensar, preguntar se identifican con la disposición de escuchar siempre la palabra que se dirige a nosotros. Sin escuchar la palabra que nos habla, nada podríamos pensar ni decir.

En sus últimos escritos, Heidegger, expresará con claridad no solo que la palabra es la casa del ser sino que "la palabra confiere el ser a la cosa" o, como dice en otro texto, "la palabra se dice al poeta como lo que detiene y mantiene una cosa en su ser" ${ }^{\prime 4}$. Sin la palabra, el ser de las cosas se esfuma y desaparece.

\section{Conclusión}

Unos días antes de su muerte, Heidegger definió sus escritos no como obras sino como caminos o senderos - Wege nicht Werke - que son vías no muy definidas y delimitadas sobre las que hay que pasar y repasar continuamente para que puedan conservarse $^{35}$. Añadía que el recorrido de su pensamiento es el de quien camina por no bien trazados senderos de montaña - Wegefeld, Holzswege - y continuamente hace preguntas para no perderse. Caminar preguntando es la mejor manera de definir el pensamiento siempre abierto de Heidegger. Si la apertura, la permanente posibilidad de ser y de hacerse es la característica fundamental del ser del Dasein, el pensamiento y la palabra como pregunta son modos esenciales de ese ser abierto, de esa vida humana abierta a su mundo que es el Dasein. Pero los caminos y las preguntas tienen siempre un inicio, un punto de partida y una dirección que podrá modificarse en la medida que avanzan. Se parte de un punto geográfico y se camina en alguna dirección, aunque ésta no esté determinada de antemano. Se pregunta a partir de los intereses previos y del pre-saber de quien pregunta. Toda pregunta supone un interés y una intención previas relacionados con el pre-saber de quien pregunta. El camino del pensamiento y de la palabra se inicia a partir de la tradición a la que el caminante que pregunta pertenece. Y la dirección de ese camino y de ese pregunta va dirigida, en Heidegger, a la polifacética realidad del ser. La tradición a partir de la que Heidegger inicia su camino preguntando es la tradición occidental jalonada por momentos importantes como son el pensamiento de Platón, de

33 Unterwegs zur Sprache, p. 175: "Jeder Ansatz jeder Frage hält sich schon innerhalb der Zusage dessen auf, was in die Frage gestellt wird [...] die Frage nicht die eigentliche Gebärde des Denkens ist, sondern der Hören der Zusage dessen, was in die Frage kommen soll".

34 Unterwegs zur Sprache, p. 164 y 168: "Das Wort verschafft dem Ding erst das Sein [...] das Wort sagt sich dem Dichter als das zu, was ein Ding in dessen Sein hält und erhält".

35 HEIDEGGER, M. Gesamtausgabe. Band I. Frühe Schrifte, p. 437: "'Wege - nicht Werke' ist der Leitspruch, den Martin Heidegger wenige Tage vor seinem Tod für seine Gesamtausgabe letzter Hand zusammen mit dem Titelblatt handschriftlich aufsetzte". 
Aristóteles, de Tomás de Aquino, de Duns Escoto, de Descartes, de Kant, de Nietzsche, de Franz Brentano y de Edmund Husserl. Tradición con la que se identifica y de la que, a la vez, se esfuerza por separarse. Si la tradición occidental ha sido una reiterada pregunta por el ser, para Heidegger esa pregunta más que una llamada por el ser para traerlo a presencia, ha sido una pregunta que ha servido para ocultarlo y olvidarlo, Seins Vergessenheit. De Sócrates hasta su tiempo, el ser determinado y singular que existe en un espacio y en tiempo, es olvidado. Es la abstracta realidad de la sustancia, de la forma y de la esencia la que se mantiene en el horizonte de esa pregunta por el ser. Sustancia, forma y esencia eternas e inmutables que pertenecen al mundo inteligible absolutamente otro y distinto de los seres que nos circundan. Duns Escoto y la Escuela franciscana iniciarán un camino nuevo en el que la pregunta por el ser conduce al ser concreto, a ser éste, a la haecceitas que singulariza, perfeccionándola, la naturaleza común que ha dejado de ser universal para convertirse en una realidad indiferente o neutra, la cual, en sí misma, no es ni universal ni singular. La valoración del individuo, especialmente el individuo humano con la capacidad volitiva de auto-determinarse y de elegir, llamará la atención del joven filósofo Martín. Dedicará a Duns Escoto su Tesis de Habilitación (1915) sobre dos preguntas a las que ha de volver sin cesar en el zigzagueante y siempre abierto sendero que es su pensamiento: las categorías como múltiples y distintos modos de ser, y la significación de los nombres, como expresión del ser en cuanto objeto conocido. Duns Escoto no será nombrado o citado por Heidegger en sus escritos a partir de 1915, para traerlo a la presencia y presentarlo a sus lectores. Duns Escoto quedará siempre en un segundo plano, oculto en el inconsciente y formando parte con Aristóteles, Kant, Nietzsche, Brentano y Husserl - del fundamento o pre-saber de Heidegger a partir del que inicia su camino de preguntas sobre el ser. En este trabajo hemos intentado develar el rastro profundo dejado por Duns Escoto en el pensamiento de Heidegger, señalando cómo preguntas fundamentales del pensamiento escotista, como la heceidad, la libertad entendida como posibilidad de elegir, al menos, entre dos alternativas, la contingencia o radical posibilidad de ser de otra manera o de dejar de ser, la relación del pensar y el decir, se encuentran también retomadas por el autor existencialista, pero hechas a partir de otro horizonte y otro contexto muy distinto. El camino que Heidegger abre con su continuo preguntar, es, sin duda, muy distinto del abierto siete siglos antes por el Ilustre Franciscano. Puede, sin embargo, descubrirse en ese camino heideggeriano señales y signos que lo refieren y lo remiten a Juan Duns Escoto. 